\title{
Erratum to: A nomogram based on mammary ductoscopic indicators for evaluating the risk of breast cancer in intraductal neoplasms with nipple discharge
}

Zhen-Qiang Lian' ${ }^{1}$ Qi Wang ${ }^{1}$ An-Qin Zhang ${ }^{1} \cdot$ Jiang-Yu Zhang $^{2}$ •

Xiao-Rong $\mathrm{Han}^{1} \cdot \mathrm{Hai}-$ Yun $\mathrm{Yu}^{1} \cdot \mathrm{Si}-\mathrm{Mei} \mathrm{Xie}^{1}$

Published online: 19 February 2016

(C) Springer Science+Business Media New York 2016

Erratum to: Breast Cancer Res Treat (2015)

150:373-380

DOI 10.1007/s10549-015-3320-8

In the original publication of the article, the affiliation of the authors has been published incorrectly. The correct affiliation of the authors appears in this erratum.

The online version of the original article can be found under doi: 10.1007/s10549-015-3320-8.

Qi Wang

wangqigz@hotmail.com

Zhen-Qiang Lian

doctorlian@qq.com

1 Breast Disease Center, Guangdong Women and Children Hospital, Guangzhou 511400, People's Republic of China

2 Department of Pathology, Guangdong Women and Children Hospital, Guangzhou 511400, People's Republic of China 